TEI

OURNAL OF THE
Journal of the Text Encoding Initiative

Issue 4 | March 2013

Selected Papers from the 2011 TEI Conference

\title{
The Project "Berlin Intellectuals 1800-1830" between Research and Teaching
}

Anne Baillot and Sabine Seifert

\section{OpenEdition}

\section{Journals}

Electronic version

URL: http://journals.openedition.org/jtei/707

DOI: $10.4000 /$ jtei. 707

ISSN: 2162-5603

Publisher

TEl Consortium

\section{Electronic reference}

Anne Baillot and Sabine Seifert, « The Project "Berlin Intellectuals 1800-1830" between Research and Teaching », Journal of the Text Encoding Initiative [Online], Issue 4 | March 2013, Online since 28

February 2013, connection on 10 December 2020. URL : http://journals.openedition.org/jtei/707 DOI : https://doi.org/10.4000/jtei.707

This text was automatically generated on 10 December 2020.

TEl Consortium 2013 (Creative Commons Attribution-NoDerivs 3.0 Unported License) 


\title{
The Project "Berlin Intellectuals 1800-1830" between Research and Teaching
}

\author{
Anne Baillot and Sabine Seifert
}

\section{The Digital Edition Letters and Texts: Intellectual Berlin around 1800}

1 Research on literary, artistic, and scholarly activity in Berlin in the late 18th and early 19th centuries has been gaining traction over recent decades (Wilhelmy-Dollinger 2000; Ziolkowski 2002; Preußen-Zentrum ${ }^{1}$ and its publications). The massive influence of political events (the French Revolution, political and economic reforms, and the Napoleonic Wars) on literary and scholarly activity throughout Europe constitutes the premise of the DFG-funded junior research project "Berlin Intellectuals 1800-1830." The constitution of a structured public sphere during the 18th century and the intensity of political life turned scholars and writers into intellectuals eager to transport a political message connected to the way they conceived their social position, especially in the context of the Prussian capital city (Berding 1994; Giesen 1993).

2 The project "Berlin Intellectuals 1800-1830" explores specific aspects of this research area. It aims at reconstructing intellectual networks through four focuses. These focuses on the one hand add to existing research projects (such as "Berliner Klassik"2, based at the Academy of Sciences) and on the other hand are in themselves representative of major tendencies. The four focuses are:

- the influence of French culture (mainly through Huguenot refugees, scholars invited by Frederick II, and post-revolution emigrants) in the constitution of these networks

- communication strategies developed by men and women writers and their differences

- the presence of political questions in literary or scholarly debates

- the role played by the creation of the University of Berlin in 1810 in the development of local and European networks 
3 The digital edition Letters and Texts ${ }^{3}$ aims to support the hypothesis that these four focuses can provide new contributions to this research area. It contains edited documents-manuscripts that had not yet been published or had only been published in part-that originate from writers, scholars, and publishers who contributed to the intellectual activity in Berlin around 1800 either through their publishing business or by giving lectures, by frequenting salons and scholarly societies (Motschmann 2009), or even by bringing together major actors, as is often the case for networkers like the salonnières, who did not leave behind a published oeuvre. Most of these edited documents are letters; other texts include manuscripts of literary texts, official documents related to both the University of Berlin (from its founding in 1810 onwards) and the Academy of Sciences, and lecture notes taken in classes given at the university in its first decades. The idea to present these handwritten documents online evolved from the implementation of a small software program (Refine!Editor, as described in Martin and Thomas 2008) to the development of an original edition, in which the researchers themselves work with XML/TEI.

The digital edition thus fosters scholarship on the basis of this material and its digital presentation in order to describe in more detail the intellectual networks in Berlin around 1800. This description is based on observations connected to persons and their relationships as well as to publications, taking into account their genesis and first reception. We consider the evolution of these two aspects between 1760 and 1848 .

\subsection{Letters and Other Pieces of Evidence}

5 The digital edition's emphasis on letters is determined by the literary practice of the period studied in the project: letters were a very popular medium in Europe around 1800. While many of them had a clearly public character, some were written for private use only, circulating in circles of various sizes. They were handed around, read aloud, and printed in various forms. Published editions of letters and correspondence were frequently prepared and revised either by the writers themselves or by a friend or family member. These editions do not compare with today's standards for scholarly editions: for example, during the 19th century, it was common practice not to mention and not to mark the changes and omissions that were implemented in the text during the editing process. If some of these texts can be easily recognized thanks to the prominence of their authors (Tieck, Chamisso, Boeckh), a significant part of the edition's various corpora emanates from authors that are not well known, and it is mostly these authors who shed new light on the well-known ones. The composition of the corpora hence aims to question the established canon of Romantic literature and the history of the humanities (as described in Flanders 2009).

6 A prototype of the digital edition, released in April 2012, includes selected letters and manuscripts. The letters are the first edited texts in two epistolary corpora: selected letters from Adolf Friedrich von Buch to Louis de Beausobre and from Ludwig Tieck to Friedrich von Raumer. The Berlin State Library - Prussian Cultural Heritage is in possession of 58 letters from Adolf Friedrich von Buch (1733-1811), a Prussian diplomat, to Louis de Beausobre (1730-1783), a privy councilor in Berlin, member of the Academy of Sciences, and author of several philosophical works. These documents, all in French, provide information on the reception of French literature (especially the part of it that was likely to spread outside France's borders thanks to reviews in 
journals) as well as on the role Huguenots played as part of the intellectual elite under Frederick II-within the Academy of Sciences (Jean Henri Samuel Formey is a key actor in this context), in education at large, and in the public sphere in general. This corpus is the most comprehensive one in the Beausobre papers and will be augmented with letters from Beausobre to Formey from the Fonds Formey, another set of papers held at the Berlin State Library - Prussian Cultural Heritage.

The letters from Ludwig Tieck to Friedrich von Raumer constitute the second corpus of letters. These letters had been published only in fragments; we will present all 55 letters from 1815 to 1846, which are also kept at the Berlin State Library - Prussian Cultural Heritage. Ludwig Tieck, a major German Romantic writer, was a long-time friend of Friedrich von Raumer (1871-1873), himself a politician and historian. Tieck and von Raumer discuss their own publications and works in progress but also all kinds of literary and political events-not to mention Tieck's never-ending money problems. These letters provide excellent material regarding the question of financial and intellectual autonomy of early 19th-century writers.

In addition to these letters, we have edited some draft manuscripts of literary texts. The early drama "Roxane" by Ludwig Tieck, written around 1789, is being published at full length for the first time. The manuscript of this unfinished verse drama, housed at the Berlin State Library - Prussian Cultural Heritage, consists of 58 folios and illuminates Tieck's early work, his literary influences, and his development as a writer. Tieck's own corrections as well as marginalia about the plot and the protagonists by his friend Wilhelm Heinrich Wackenroder (1773-1798) offer a deeper knowledge of his writing process as well as the intellectual genesis of this early drama.

Also included in the April 2012 release is the edited manuscript of the Romantic novella "Der Sandmann" by E. T. A. Hoffmann, based on the handwritten manuscript in the literary estate of the publisher and writer Julius Eduard Hitzig (1780-1859), kept at the Stiftung Stadtmuseum Berlin. This manuscript dates from 1815 and consists of 35 pages. It shows comments and changes by Hoffmann himself and thus mirrors his writing process. Manuscripts of Friedrich de La Motte-Fouqué's "Undine" (version for opera, 1812) and Adelbert von Chamisso's "Peter Schlemihls wundersame Geschichte" (copy from 1814) can also be found in the literary estate of Hitzig, who was a friend and advisor in literary affairs to both of them. The joint edition of these manuscripts -"Undine" and "Schlemihl" will follow in 2013-provides a new reading of their connections, differences, and their respective genesis. The edition of letters by Adelbert von Chamisso to his friend Louis de La Foye, which will be prepared in conjunction with courses on scholarly editions taught in the summer semester 2012 and the winter semester 2012/13 (see section 2 below), will shed light, among other things, on the genesis of "Schlemihl" and the journal Musenalmanach (Klussmann and Mix 1998).

The digital edition will continue to be developed until 2015. Further letters and manuscripts by the aforementioned writers and scholars will be added, together with writings by other intellectuals. The edition, more details on the several corpora, and the editorial guidelines can be found at http://tei.ibi.hu-berlin.de/berlinerintellektuelle. 


\subsection{Editorial Decisions and Technical Implementation}

11 From thinking about a basic online edition we quickly moved on to develop a TEI-based implementation that fulfills the varying demands of our text corpora. Due to the fact that there is not yet a ready-to-use customization for letters and correspondence within TEI P5 (TEI Consortium 2012), we had to pay special attention to the requirements of encoding correspondence and design a letter-specific manuscript description. We were inspired by valuable online editions of correspondences, such as Vincent van Gogh: The Letters (Jansen, Luijten, and Bakker 2009) and the Carl-Maria-vonWeber-Gesamtausgabe ${ }^{4}$, and consulted the work of the TEI Special Interest Group on Correspondence. ${ }^{5}$ We developed our own editorial guidelines and set up an eXist database at the Berlin School of Library and Information Science at Humboldt University.

Unlike the Heinrich-Heine-Portal ${ }^{6}$ and the Digitale Faustedition, ${ }^{7}$ we do not aim to provide a complete historical-critical edition of our documents. Our edition offers a reliable literal transcription as well as local explanations for text passages too obscure to be understood out of context. The encoding work consists in marking up elements immediately derived from the materiality of the manuscript (such as stains, holes, missing parts, change of ink, or intrusion of other hands) that are relevant to its literary and historical comprehension. The specificities of the Old German script, and especially the difference between passages in Old German script and those in Latin script, are rendered as well. More importantly, the markup extends to dates, people, place names, names of journals and other works, and institutions. These elements work as combinable keys and make it possible to search the whole corpus for network structures revolving around those elements. The representativeness of the edited texts allows the reader to actually retrace the life cycle of important literary works from their genesis to their first reception throughout all of our corpora. The first corpora already reveal that Rousseau's Émile (1762) and A. W. Schlegel's Vorlesungen über dramatische Kunst und Literatur (1809-1811) play a transversally structuring role among the other works in these corpora. It thus becomes possible to evaluate the impact of political or literary events in a given period of time or in the context of precise intellectual circles, be they formal societies or informal friend networks.

The web interface of the edition is designed to appeal both to scholars and to general readers. The screen is divided into two columns that each show six tabs. These tabs allow the reader to display up to two of the six possible views:

1. the facsimile of the manuscript page

2. the diplomatic transcription (showing additions, deletions, mistakes, the foliation, and all notes left by other persons like archivists or editors)

3. the edited text (showing only the hand(s) of the author, in which the manuscript's line breaks do not appear, missing text passages are reconstituted, and abbreviations are written out)

4. the list of entities (persons, places, and works mentioned on the page of the document being viewed and in the whole document)

5. the XML file with the TEI encoding

6. the metadata

The encoding is made available under a CC-BY license. 
The next steps in the work of reconstructing intellectual networks include scaling up the encoding operation (to make available more edited text and do additional work on the general architecture of the edition), development of collation methods (encoding, visualization, and a method of textual analysis shedding light on the author's and publisher's contributions to the genesis of the text), and a more general reflection on how to visualize these networks beyond the local analysis of genesis or the reception of a single literary or scholarly work.

It becomes apparent that the very structure of this edition differs from that of traditional historical-critical editions, as well as from most of the digital ones. In particular, the decision to present the transcription in two views-the diplomatic transcription and the edited text-seems to be a very unusual feature, although the digital medium, in contrast to print, is especially suited for that. This decision was based on the aim to address both the scholarly community and the interested public. The unified structure of the edition also makes it inviting for non-scholars and students to make a contribution.

\section{Teaching an "Introduction to Digital Humanities"}

7 Using Letters and Texts as the basis for a class that introduces students to digital humanities in general, and the TEI in particular, was a methodical and intellectual challenge. The edition was, at the time of the class, still at an early stage and provided for very few answers for the students. Working with it in class helped the students to develop relevant questions rather than provide them with final answers.

Anne Baillot and Laurent Romary were responsible for the class, but guest lecturers were also invited to present their own projects. We discussed the impact of digital humanities on literary studies and taught students the basics needed to create their own editions. The seminar was designed for master's students in the degree program in European Literatures, which offers a praxis module into which the encoding part of the class fitted perfectly. Students came from very different academic backgrounds. Some of them-mainly those who had previously studied linguistics at Humboldt Universityalready had some experience with XML. None of them were familiar with the TEI.

\subsection{Encoding at Work}

Being taught practical, usable skills appealed to all the students. The first session, however, revealed that they had come to the class with different, if not opposite, backgrounds. Some had done encoding before, partly in another language than XML, and wanted to deal with it in more detail. Others enrolled because of their lack of knowledge of digital humanities and subsequent curiosity. The discussion of existing digital editions that were presented during the first sessions revealed the students' remarkable capacity to connect literary theory, as they had learned it in traditional literary curricula, to a digital approach. These lively debates were very promising. Once they started encoding their documents, however, they became focused on their own projects to such an extent that the general discussion was not as rich as the first sessions had led us to hope. 
The students' evaluation was based on two assignments: one was their encoding of a document and the other the writing of an essay on their encoding. At the beginning of the term, we presented a range of handwritten documents, all of them likely to be part of Letters and Texts: letters in German, French, or English, lists of students, lecture notes, and official papers, some of them documenting the creation of the University library. We invited each student to choose one of these documents to encode.

One particularly talented student picked a lecture notes manuscript that connected together several sets of notes taken by different persons during the same lecture. He was interested in the challenge of encoding one page of a particularly complex document and mastered the difficult requirements very well. The following is his $<$ handNotes $>$ section of the header:

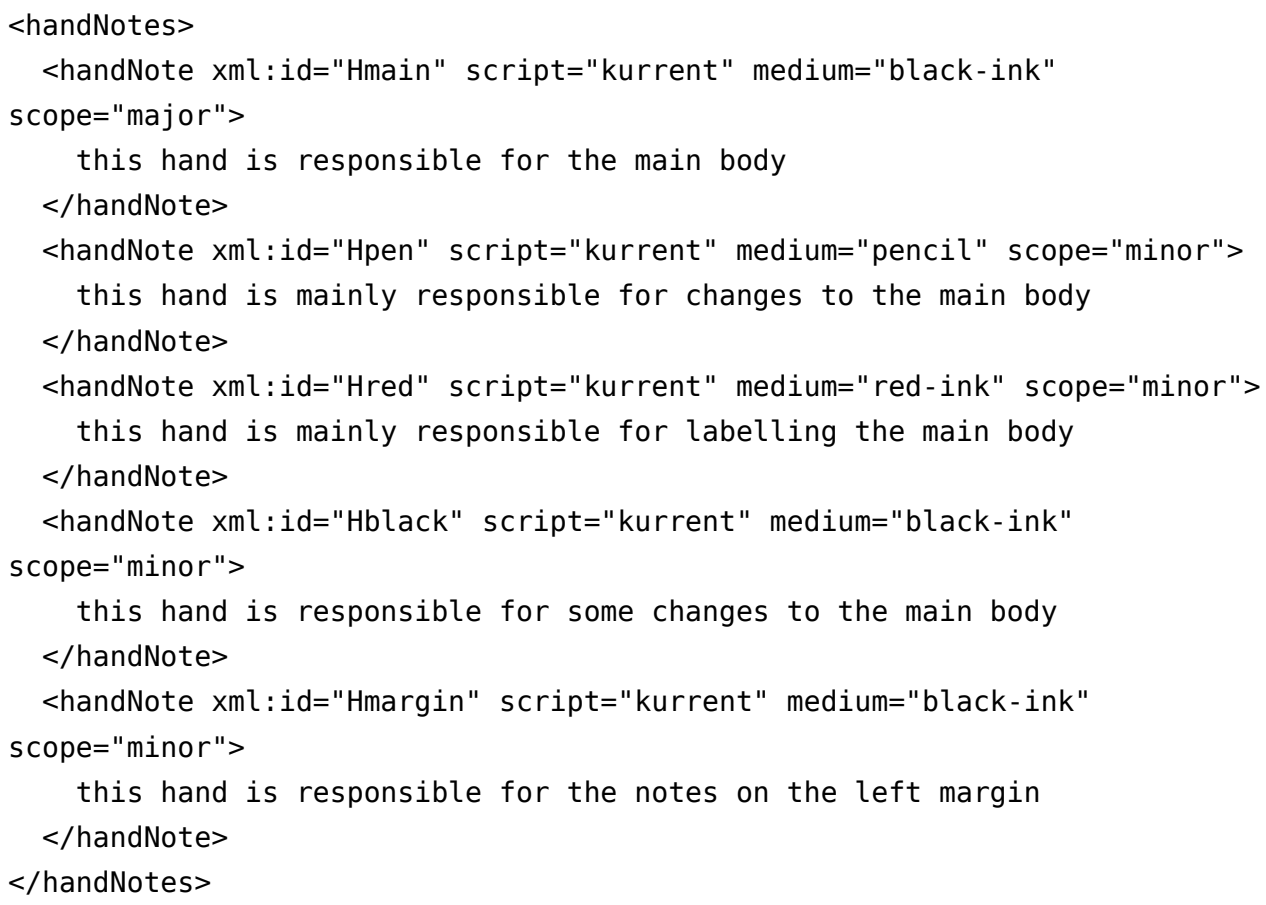

22 We can see that the student developed a detailed system of differentiating the several hands regarding their function in the manuscript. And in this way he implemented this concept in his encoding of the editorial process at work in the manuscript: 

following letter by Chamisso to de La Foye (fig. 1), which contains the hand of Chamisso; the hand of the publisher, probably Hitzig, adding a place name and deleting passages for the print version; the hand dating the letter; and one or two hands writing down archival numbers:

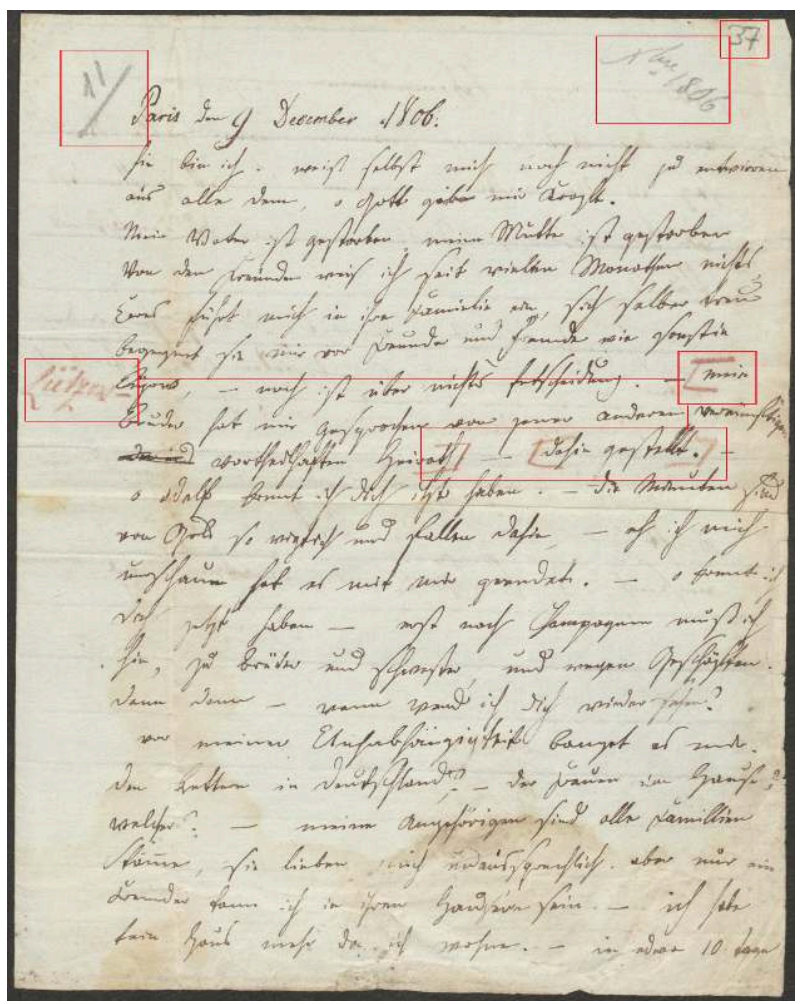

Figure 1. Letter from Chamisso to de La Foye (Source: Berlin State Library - Prussian Cultural Heritage, de La Foye papers, NL 239, Bl. 37)

On the visualization side, we decided not to try to render the variety of textures or colors presented by the different hands since it would have been beyond our technical resources in terms of graphic interface. Still, it was necessary to mark a difference in the level of authority of each hand. Only the "major hand" appears in the edited text, as the authoritative one. However, if the author has more than one hand, then all his or her hands are shown. In the diplomatic version, the visualization varies regarding the function of the hands: some appear in red at the end of the page, others in square brackets at the place where they can be found on the manuscript. This visualization is still unsatisfactory and will be improved in connection with the work on the collation tool since minor hands appearing on these letters often are those of earlier editors, whose printed version we ultimately want to compare with the original.

Not all students' works resulted in such a complex and fruitful questioning within Letters and Texts. The other students decided on documents in which few hands were at work, the script rather easy to read, and the authors reasonably well known. Most of the students chose letters. Working with letters of one or two pages enabled them to encode a document from beginning to end. Thus, they were in a position to deal with a text entity that was still a manageable size. 


\subsection{Problems, Results, and Our Next Teaching Project}

European Literatures program but also in the German Literature program at Humboldt University. It did not aspire to include a theoretical reflection on digital humanities in general but instead aimed at thoroughly teaching an editorial method for digital editions. The workflow was more precisely framed, the corpus was predefined and homogenous for all students (letters from Adelbert von Chamisso to his friend Louis de La Foye), and the encoding took place in class in conjunction with the transcription work. The students used the encoding guidelines, by then much more stable, for Letters and Texts, and the incentive of having their work actually published online was a great motivation. The assignments consisted of detailing the literary pertinence of the documents that the students encoded as well as extracting compelling aspects of the encoding and of the interpretation of the texts made possible by their encoding. The visualization of their work relies completely on the XSLT stylesheet developed for Letters and Texts. Since the very minimal editorial work of the previous class had allowed a few students to deliver not only a very clean encoding but also a nice literary commentary on their letters, this class included all editorial work steps: archival search, transcription, encoding, and commenting on the literary and historical context. livelihood of the general discussion, although all students were working on bits of the same epistolary corpus. The remarkably precise encoding achieved by the students, however, not only showed their capacity to apply our edition's existing guidelines; it also pointed at problems that had been overlooked-for instance, the importance of 
overwritten letters within a word, when you cannot properly decipher the individual alphabetic characters in the first text layer but can only see that it has been overwritten. While the students consulted the Letters and Texts guidelines thoroughly, these guidelines were naturally not exhaustive, and unlike with the previous class, the students did not know where else to look for guidance.

As much as this editorial class helped Letters and Texts to move forward in terms of text quantity and specification of the encoding guidelines, it also cost a lot of time and energy to keep the inner balance of the edition with the intrusion of such an amount of external input. It requires a massive effort from the editorial team to maintain some unity in the encoding within the Chamisso corpus itself as well as within the edition more generally. This is not primarily a problem of local interpretations, which inevitably are subjective and delicate to deal with in crowdsourced projects: we knew from the beginning that we would have to deal with these. Instead, the main difficulty has to do with the fact that the students consider their encoding as an individual creation and tend to disregard questions of economy and general philosophy on the larger scale of the actual edition.

\section{Conclusion: Digital Humanities in Literary Curricula}

In 1810, Wilhelm von Humboldt founded a university of a new type in Germany: one that aimed to bring together research and teaching. But ever since then, it has proven a difficult task to actually reunite them, mostly because the two requirements of openness towards students and scholarly accuracy often seem irreconcilable. The structure of the digital edition Letters and Texts offers both. The second class taught in the summer term of 2012 showed the high level of motivation and the impressive amount of work that students can invest in a teaching project when it comes to taking part in real research.

Research as well as teaching gains greatly from flexible and open interaction with students. Students of literary curricula who often are confronted with the "uselessness" of what they are being taught appreciate the user-orientation of Webbased projects and invest great reflection and energy in such class projects. Meanwhile, editors have to confront the questions that arise in the classroom, as well as make people-especially generations of future users-aware of the depth and complexity of digital editing.

German universities have developed specific curricula for edition philology, for example at the Freie Universität Berlin, as well as curricula for digital humanities, for example at the universities of Würzburg and, in the near future, Göttingen. But good digital practice should at some point appear in all literary curricula, be it in the form of a work on a digital edition that allows deconstruction of the myth of WYSIWYG, discussions on open access, or learning how to properly use digital tools like Wikipedia, which students systematically use in their preparation of classes, papers, and assignments. They do so without orientation, which leads to unsatisfactory use of online editions, improper ways of quoting, and a lack of assessment of the reliability of the information they find on the Internet. These aspects are most problematic in a system in which writing research papers is a fundamental element of the curriculum. Introducing good digital humanities practice seminars early in the curriculum, 
covering questions of digital infrastructure and how it affects the way we read texts, would benefit both the students and the curricula.

\section{BIBLIOGRAPHY}

Berding, Helmut, ed. 1994. Nationales Bewußtsein und kollektive Identität. Frankfurt am Main: Suhrkamp.

Flanders, Julia. 2009. "The Productive Unease of 21st-century Digital Scholarship." Digital Humanities Quarterly 3.3. http://www.digitalhumanities.org/dhq/vol/3/3/000055/000055.html. Giesen, Bernhard, ed. 1993. Die Intellektuellen und die Nation. Frankfurt am Main: Suhrkamp. Jansen, Leo, Hans Luijten, and Nienke Bakker, eds. 2009. Vincent van Gogh: The Letters. Version: December 2010. Amsterdam \& The Hague: Van Gogh Museum \& Huygens ING. http:// vangoghletters.org.

Klussmann, Paul Gerhard, and York-Gothart Mix, eds. 1998. Literarische Leitmedien: Almanach und Taschenbuch im kulturwissenschaftlichen Kontext. Wiesbaden: Harrassowitz.

Märtin, Björn, and Christian Thomas. 2008. "Das Wuchern der Archive. Die digitale Edition des Nachlasses Franz Brümmer mit dem Refine!Editor." Editio. Internationales Jahrbuch für Editionswissenschaft 22: 204-12.

Motschmann, Uta. 2009. Schule des Geistes, des Geschmacks und der Geselligkeit: die Gesellschaft der Freunde der Humanität (1797-1861). Hannover: Wehrhahn.

TEI Consortium. 2012. TEI P5: Guidelines for Electronic Text Encoding and Interchange, edited by Lou Burnard and Syd Bauman. Version 2.1.0. Last updated June 17. N.p.: TEI Consortium. http:// www.tei-c.org/release/doc/tei-p5-doc/en/html/index.html.

Wilhelmy-Dollinger, Petra. 2000. Die Berliner Salons. Mit historisch-literarischen Spaziergängen. Berlin: De Gruyter.

Ziolkowski, Theodore. 2002. Berlin: Aufstieg einer Kulturmetropole um 1810. Stuttgart: Klett-Cotta.

\section{NOTES}

1. http://zentrumpreussen.bbaw.de

2. http://www.berliner-klassik.de

3. http://tei.ibi.hu-berlin.de/berliner-intellektuelle; English: http://tei.ibi.huberlin.de/berliner-intellektuelle/?language $=$ en

4. http://www.weber-gesamtausgabe.de/

5. http://www.tei-c.org/Activities/SIG/Correspondence

6. http://www.hhp.uni-trier.de/

7. http://www.faustedition.net/ 
INDEX

Keywords: German literature, Romanticism, letters, teaching, manuscript editions

\section{AUTHORS}

\section{ANNE BAILLOT}

Anne Baillot is a junior research group leader at the Institute for German Literature of the Humboldt University in Berlin. She leads a DFG-funded project on intellectual networks in Berlin in the late 18th-early 19th century. http://www.anne-baillot.eu; blog on development of the digital edition: http://digitalintellectuals.hypotheses.org/.

\section{SABINE SEIFERT}

Sabine Seifert is a PhD candidate in the junior research group at the Institute for German Literature of the Humboldt University in Berlin. Her dissertation analyzes unedited manuscripts by the 19th-century philologist August Boeckh. 